Check for updates

Cite this: Chem. Sci., 2019, 10, 768

๑ All publication charges for this article have been paid for by the Royal Society of Chemistry

Received 28th August 2018

Accepted 28th October 2018

DOI: $10.1039 / \mathrm{c} 8 \mathrm{sc} 03835 \mathrm{j}$

rsc.li/chemical-science

\section{A copper-catalyzed double coupling enables a 3- step synthesis of the quassinoid core architecture $\uparrow$}

\author{
Matthew L. Condakes, (D) Rachel Z. Rosen, Stephen J. Harwood \\ and Thomas J. Maimone (D) *
}

\begin{abstract}
The quassinoids are a fascinating class of degraded triterpene natural products which possess, among other attributes, potent anti-cancer activity. Their complex polycyclic ring systems also serve as inspiration for the development of new chemical methods and strategies - especially those pertaining to $\mathrm{C}-\mathrm{C}$ bond formation. Herein we disclose a novel tandem cross coupling $/ \mathrm{S}_{\mathrm{N}} 2^{\prime}$ reaction of vicinal epoxy vinyl triflates with simple Grignard reagents catalyzed by $\mathrm{Cu}(1)$. Using this transformation, the polycyclic core architecture of the quassinoids can be generated in only three linear steps from carvone epoxide, forming five carbon-carbon bonds in the process.
\end{abstract}

\section{Introduction}

Rapid generation of molecular complexity is a major driving force for $21^{\text {st }}$ century organic synthesis, and natural products continue to provide an ideal testing ground for such exploration. ${ }^{1}$ In particular, the highly complex family of quassinoid natural products appears to be an area wherein novel methodologies could lead to great synthetic simplification. Derived from triterpenes, quassinoids are characterized by a tetracyclic ring system often containing a D-ring lactone (see 1-4, Fig. 1A). ${ }^{2}$ Moreover, the exciting biological profiles displayed by many quassinoids - particularly potent anti-cancer activity - provides an additional biological impetus for synthetic exploration. ${ }^{3}$ Not surprisingly, this family of natural products have historically been popular synthetic targets and have succumbed to multiple total synthesis efforts over the past several decades. ${ }^{4-6}$

We identified a hypothetical double vinylation transform of a chiral pool monoterpene as a way of accessing $\mathbf{5}$, an intermediate we envisioned advancing to the quassinoid ring system (see 6) by way of two successive ring-forming reactions (Fig. 1B). ${ }^{7}$ Inspired by Wender's report of various organometallic reagents engaging epoxy enol ethers, enol phosphates, and enolates in $\mathrm{S}_{\mathrm{N}} 2^{\prime}$ reactions, ${ }^{8}$ and McMurry's seminal work on the cross coupling of vinyl triflates with cuprates, ${ }^{9}$ we envisioned developing a $\mathrm{Cu}(\mathrm{I})$-catalyzed process to convert carvone epoxide (7) directly into functionalized cyclohexenol 9 by way of vinyl triflate 8 and simple Grignard reagents (Fig. 1C). In

Department of Chemistry, University of California, Berkeley, 826 Latimer Hall, Berkeley, California 94720, USA. E-mail: maimone@berkeley.edu

$\uparrow$ Electronic supplementary information (ESI) available: Experimental procedures, compound characterization data, and X-ray crystallographic data of compounds 18, 21, 32, 33, 35, and 38. CCDC 1856948, 1856946, 1856945, 1856947, 1856950, 1856949 respectively. For ESI and crystallographic data in CIF or other electronic format see DOI: $10.1039 / \mathrm{c} 8 \mathrm{sc} 03835 \mathrm{j}$ principle, this reaction could formally introduce two $\mathrm{sp}^{2}$ fragments in a single step and with high diastereocontrol. From the outset, however, we were aware of the paucity of Kumada-type couplings of vinyl triflates and Grignard reagents catalyzed by

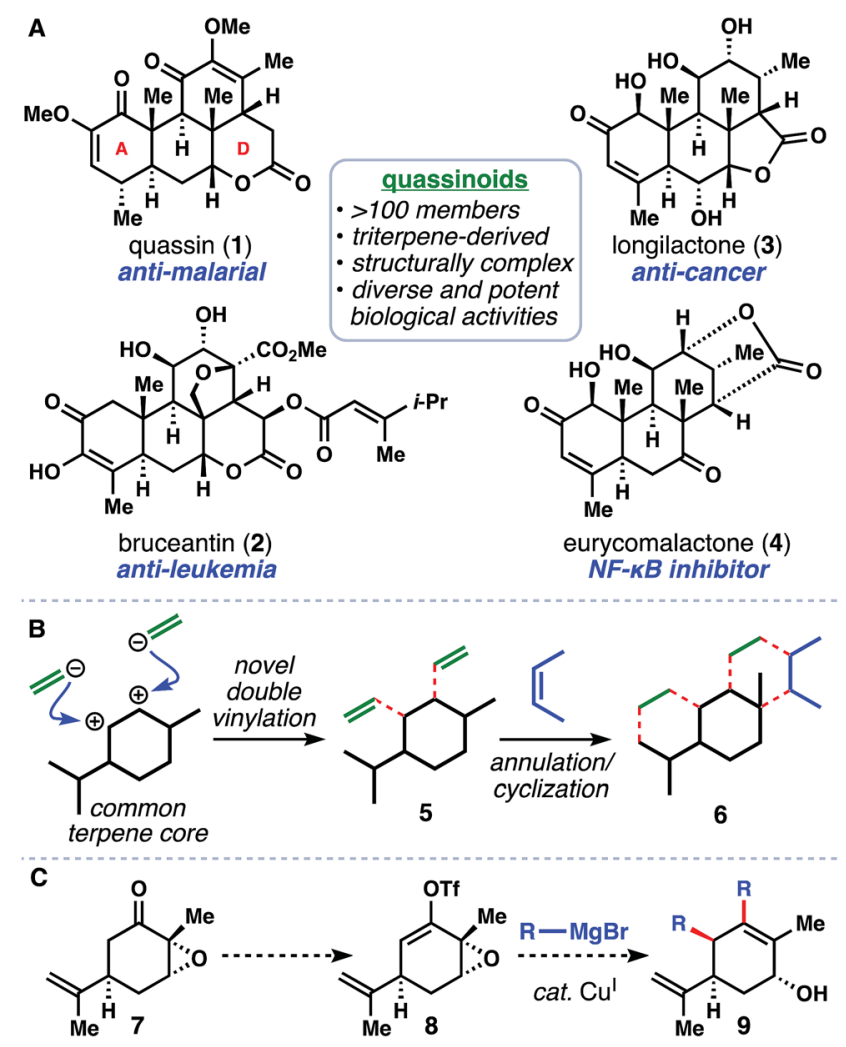

Fig. 1 (A) Selected quassinoid natural products and their associated biological activities. (B) Synthetic strategy to access the quassinoid architecture featuring a novel double coupling reaction and successive cyclizations. (C) Desired coupling methodology. 
copper, a preferred metal for $\mathrm{S}_{\mathrm{N}} 2^{\prime}$ substitution processes. ${ }^{10,11}$ Moreover, a mechanism by which we could distinguish between the cross-coupling and allylic substitution reactivities would be ideal in realizing the selective coupling of two different nucleophiles, but potentially challenging to implement given the similarities between the two reaction modalities. Herein we realize the one-pot double coupling of epoxy ketones with Grignard reagents catalyzed by a $\mathrm{Cu}(\mathrm{I})$ complex. Using this tandem process, we then show that the quassinoid core architecture can be accessed in only three steps, forming five C-C bonds in the process.

\section{Results and discussion}

We began our investigations by examining the model coupling of epoxy ketone 10 with methyl Grignard to form double coupled product 12 (Table 1 ). We quickly realized that it was not necessary to isolate the vinyl triflate intermediate (see 11) for this reaction to be successful, and in fact we encountered challenges in doing so for a variety of ketones, including $\mathbf{1 0}$. Much to our delight, we found that multiple copper(I) salts were competent at catalyzing this transformation, albeit with variable levels of diastereoselectivity. Most copper catalysts enforced the expected anti stereochemistry for the allylic substitution; ${ }^{12}$ however, when the copper center was ligated with a bulky NHC ligand (entry 5), a slight preference for syn stereochemistry was observed. Of the copper sources examined, tetrakis(acetonitrile)copper(I) hexafluorophosphate $\left[\mathrm{Cu}(\mathrm{MeCN})_{4}\right]\left[\mathrm{PF}_{6}\right]$ (entry 4) seemed the most promising and was thus selected for further studies.

Table 1 Selected optimization studies ${ }^{a}$

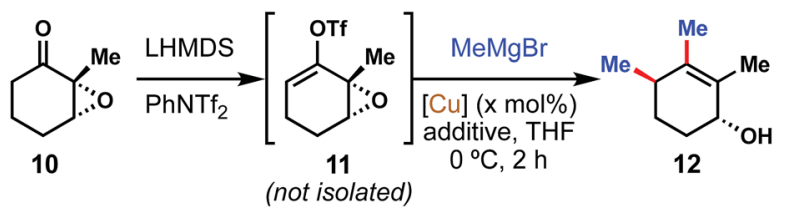

\begin{tabular}{llllll}
\hline Entry & {$[\mathrm{Cu}]$} & $X^{b}(\mathrm{~mol} \%)$ & Additive $^{c}$ & Yield $^{d}(\%)$ & d.r. $^{e}$ \\
\hline 1 & $\mathrm{CuCl}$ & 15 & - & $43 \%$ & $3: 1$ \\
2 & $\mathrm{CuBr}$ & 15 & - & $42 \%$ & $3: 1$ \\
3 & $\mathrm{Cul}$ & 15 & - & $43 \%$ & $4: 1$ \\
4 & {$\left[\mathrm{Cu}(\mathrm{MeCN})_{4}\right]\left[\mathrm{PF}_{6}\right]$} & 15 & - & $43 \%$ & $7: 1$ \\
5 & $(\mathrm{IPr}) \mathrm{CuCl}$ & 15 & - & $41 \%$ & $1: 2$ \\
$\mathbf{6}^{f}$ & {$\left[\mathrm{Cu}(\mathrm{MeCN})_{4}\right]\left[\mathrm{PF}_{6}\right]$} & $\mathbf{1 5}$ & $\mathbf{H M P A}$ & $\mathbf{4 6 \%}$ & $>\mathbf{2 0}: \mathbf{1}$ \\
7 & {$\left[\mathrm{Cu}(\mathrm{MeCN})_{4}\right]\left[\mathrm{PF}_{6}\right]$} & 15 & DMPU & $32 \%$ & $4: 1$ \\
8 & {$\left[\mathrm{Cu}(\mathrm{MeCN})_{4}\right]\left[\mathrm{PF}_{6}\right]$} & 15 & TMEDA & $23 \%$ & $4: 1$ \\
9 & {$\left[\mathrm{Cu}(\mathrm{MeCN})_{4}\right]\left[\mathrm{PF}_{6}\right]$} & 7.5 & HMPA & $23 \%$ & $>20: 1$ \\
10 & {$\left[\mathrm{Cu}(\mathrm{MeCN})_{4}\right]\left[\mathrm{PF}_{6}\right]$} & 30 & HMPA & $41 \%$ & $>20: 1$
\end{tabular}

${ }^{a}$ Standard reaction conditions: epoxide ( $0.1 \mathrm{mmol}, 1.0$ equiv.), LHMDS (0.1 mmol, 1.0 equiv.), $\mathrm{PhNTf}_{2}$ (0.1 mmol, 1.0 equiv.), $-78 \rightarrow 0{ }^{\circ} \mathrm{C}$, $5 \mathrm{~min}$; then add a solution of $\mathrm{MeMgBr}(0.3 \mathrm{mmol}, 3.0$ equiv.), [Cu] $(X \mathrm{~mol} \%)$, and additive, $0{ }^{\circ} \mathrm{C}, 1 \mathrm{~h} .{ }^{b} \mathrm{~mol} \%$ with respect to epoxide starting material. ${ }^{c}$ Additives included at 5.0 equiv. ${ }^{d}$ Isolated yield of 12 after column chromatography. ${ }^{e}$ Determined by ${ }^{1} \mathrm{H}$ NMR of the crude reaction mixture. ${ }^{f}$ Reaction performed using $1.0 \mathrm{mmol}$ of epoxide.
Diastereoselectivity could be further impacted by the inclusion of polar additives (entries 6-8). HMPA (5.0 equiv.) in particular was found to bias the allylic substation to the anti isomer almost exclusively. Varying the catalyst loading (entries $9,10)$ did not further impact diastereoselectivity but did have a deleterious effect on yield if the amount of catalyst was decreased below $15 \mathrm{~mol} \%$ ( $5 \mathrm{~mol} \%$ with respect to MeMgBr).

We then proceeded to explore the scope of this tandem coupling process (Fig. 2A). Traditionally, copper catalysis has struggled to cross-couple aryl nucleophiles, due to their decreased reactivity relative to alkyl congeners. ${ }^{10,11 a}$ Much to our delight, however, products derived from aromatic Grignard reagents with diverse substituents (13-19) were afforded cleanly and in good yield. ${ }^{13}$ Other $\mathrm{sp}^{2}$ nucleophiles relevant to the quassinoid synthetic problem including dioxenyl (20) and vinyl (21) could also be coupled, generating products as single diastereomers. Single crystal X-ray diffraction studies of $\mathbf{1 8}$ and $\mathbf{2 1}$ confirmed the anti-stereochemistry. Two substrates deserve special mention (Fig. 2B). First, 22 - the product formed when using the di-Grignard reagent derived from 2,2'-dibromobiphenyl - exclusively underwent cross-coupling and $\mathrm{S}_{\mathrm{N}} 2$ opening of the epoxide, likely due to the intramolecular, and perhaps non-catalyzed, nature of the second step. Secondly, we note that 23 - the product of coupling allyl Grignard - was formed as a $1: 1$ mixture of syn and anti diastereomers, perhaps due to the high nucleophilicity of this reagent. ${ }^{14}$

Different epoxide substrates were also well tolerated with this methodology (Fig. 2C). Replacement of the 2-methyl group with a larger phenyl group did not hinder product formation (see 24). Likewise, addition of a methyl group at the 3-position did not impact the reaction to prepare 25; however, that compound's tertiary allylic alcohol motif was highly acid sensitive and would rapidly dehydrate under even mildly acidic conditions. Products from both diastereomers of carvone epoxide $(\mathbf{2 6}, \mathbf{2 7})$ were also obtained cleanly. Notably, this system was able to override the intrinsic steric bias of cis-carvone epoxide to still deliver anti product $\mathbf{2 7}$.

Finally, we were then able to expand this methodology to perform couplings with two different nucleophiles in the same pot (Fig. 2D). We determined that at low temperatures $\left(-78^{\circ} \mathrm{C}\right)$, the cross-coupled product could be formed selectively. This intermediate could then be treated with a different nucleophile, which would only perform the allylic substitution step when warmed to $0{ }^{\circ} \mathrm{C}$. Through this process, differentially substituted products (28-32) were assembled in a modular manner. Importantly, nucleophile identity (aryl, vinyl, alkyl, etc.) did not change the selectivity of this transformation; rather, the controlling factors in all cases were order of nucleophile addition and reaction temperature. Thus, it proved straightforward to prepare regioisomeric products 31 and 32 by simply switching which one of the nucleophiles was added first. The connectivity and selectivity of $\mathbf{3 2}$ were additionally confirmed by single crystal X-ray diffraction studies.

With this methodology successfully established, we then turned our attention toward application to the quassinoid ring system (Scheme 1). We began by coupling carvone epoxide with the dioxane-based Grignard reagent to afford $\mathbf{3 3}$ as a single 

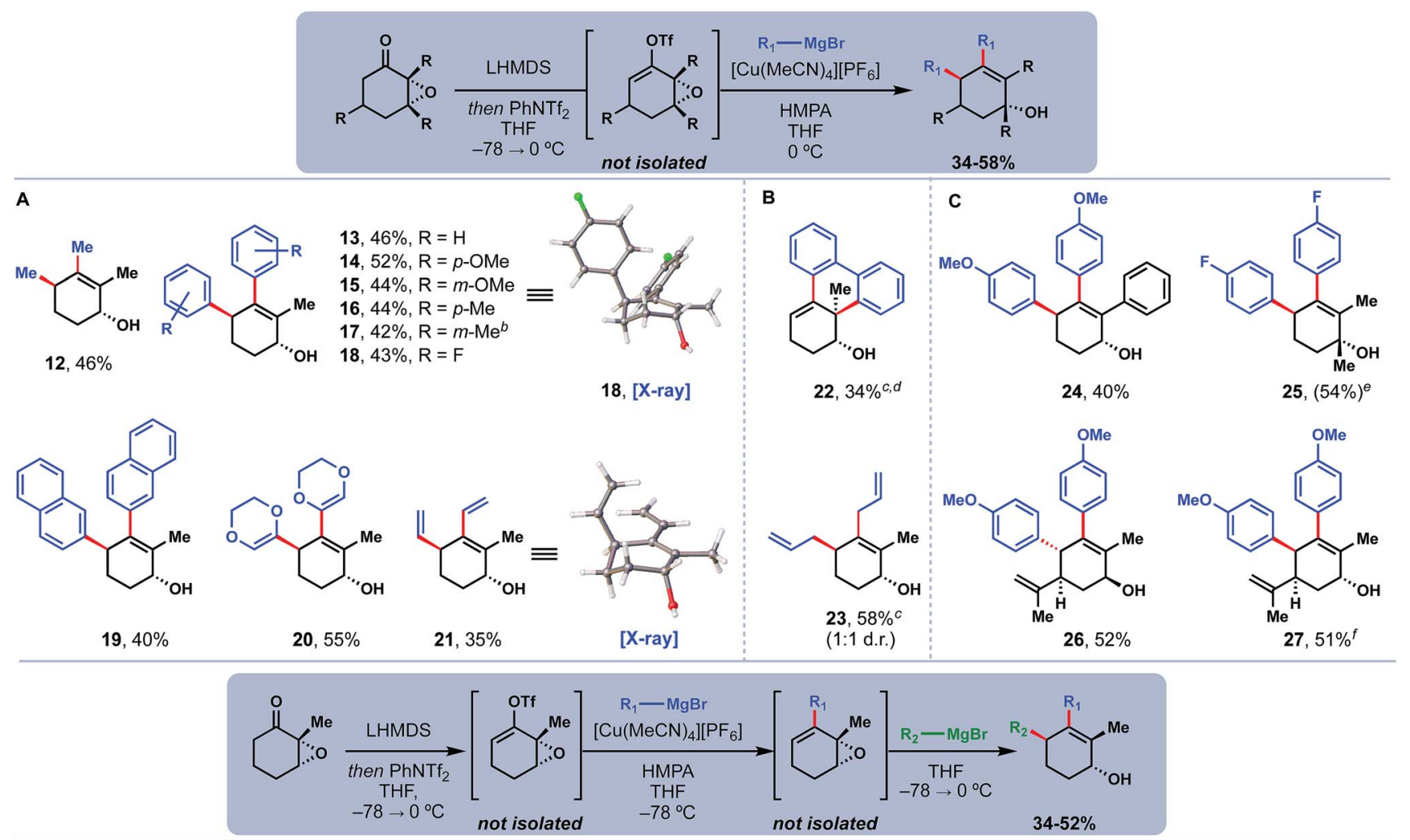

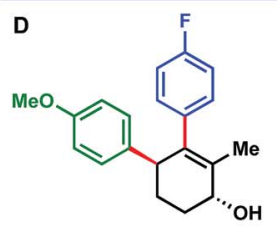

28, $52 \%$

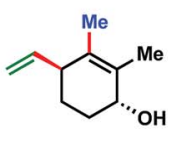

$29,34 \%$

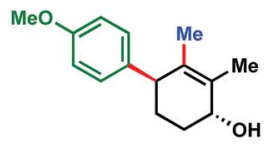

$30,48 \%$

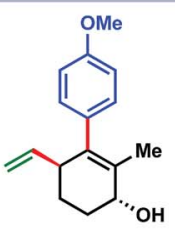

$31,48 \%$

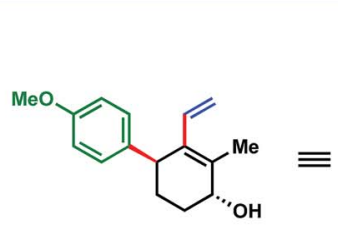

$32,50 \%$

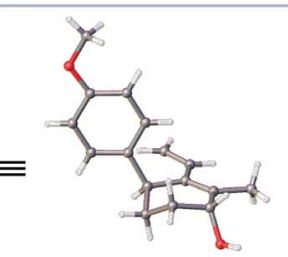

[X-ray]

Fig. 2 Copper-catalyzed double coupling of epoxy ketones and Grignard reagents: (A) Scope with two of the same Grignard reagents. (B) Anomalous products, see main text for further discussion. (C) Use of different epoxides. (D) Coupling of two different nucleophiles. ${ }^{a}$ Reactions were run with $1.0 \mathrm{mmol}$ of epoxide under the optimized conditions. Reported yields are of products isolated as single isomers, except where otherwise indicated. ${ }^{b} 10: 1$ d.r. ${ }^{c} \mathrm{Cul}$ used in place of $\left[\mathrm{Cu}(\mathrm{MeCN})_{4}\right]\left[\mathrm{PF}_{6}\right]$ and no HMPA added. ${ }^{d} 2.0$ equiv. of 2,2'-biphenyldimagnesium bromide used as nucleophile. ${ }^{e} \mathrm{NMR}$ yield using 1,3,5-trimethoxybenzene as an internal standard. ${ }^{f} 30 \mathrm{~mol} \%$ loading of $\left[\mathrm{Cu}(\mathrm{MeCN})_{4}\right]\left[\mathrm{PF}_{6}\right]$ used.

isomer in $58 \%$ yield; the anti stereochemistry of the product was confirmed by X-ray crystallographic analysis. Notably, we have been able to prepare multiple grams of this unique product using this chemistry. At this point, we reasoned that the C- and D-rings of the quassinoids could be forged through an intramolecular Diels-Alder reaction of the vinyl dioxane fragment with a dienophile side chain tethered to allylic alcohol $33 .^{15,16}$ Many initial attempts to realize this transformation were foiled due to the significant lability of the allylic alcohol under thermal and acidic conditions. Eventually we determined that the depicted methyl chloroalkyl ether could first alkylate the free alcohol under basic conditions (DIPEA), creating a pair of diastereomeric acetals ( $c a .1: 1$ d.r.) that would then undergo the Diels-Alder reaction upon further heating. Interestingly, the acetal stereochemistry exerted a strong controlling effect on the endo/exo selectivity of the cycloaddition reaction. Specifically, one acetal isomer gave exclusively the endo product (34) while the other favored exo product 35 over endo product 36 ( $c a .3: 1$ exo : endo). Overall, this led to isolation of two major diastereomers, 34 and 35 - one endo isomer and one exo isomer (1.3: 1 d.r.) - which were used in subsequent chemistry. The stereochemistry of the exo product $\mathbf{3 5}$ was confirmed by single crystal X-ray diffraction studies (see ESI $\dagger$ ). Although $\mathbf{3 4}$ and 35 differed in three stereocenters, they were carried forward as a mixture since we anticipated epimerization or ablation of those centers before arriving at various quassinoid natural products. ${ }^{17}$

To complete the quassinoid core architecture, we envisioned a cascade dioxane oxidation/rearrangement/cyclization to form the A-ring. Prior work by Hanna and co-workers demonstrated that epoxidation of substituted dioxenes and rearrangement to an aldehyde occurs readily. ${ }^{18}$ In our case, we wondered whether an acid could be identified that not only performed this rearrangement, but also promoted an intramolecular ene reaction between the newly formed aldehyde and the neighboring isopropenyl group. In practice, the desired epoxide intermediate 

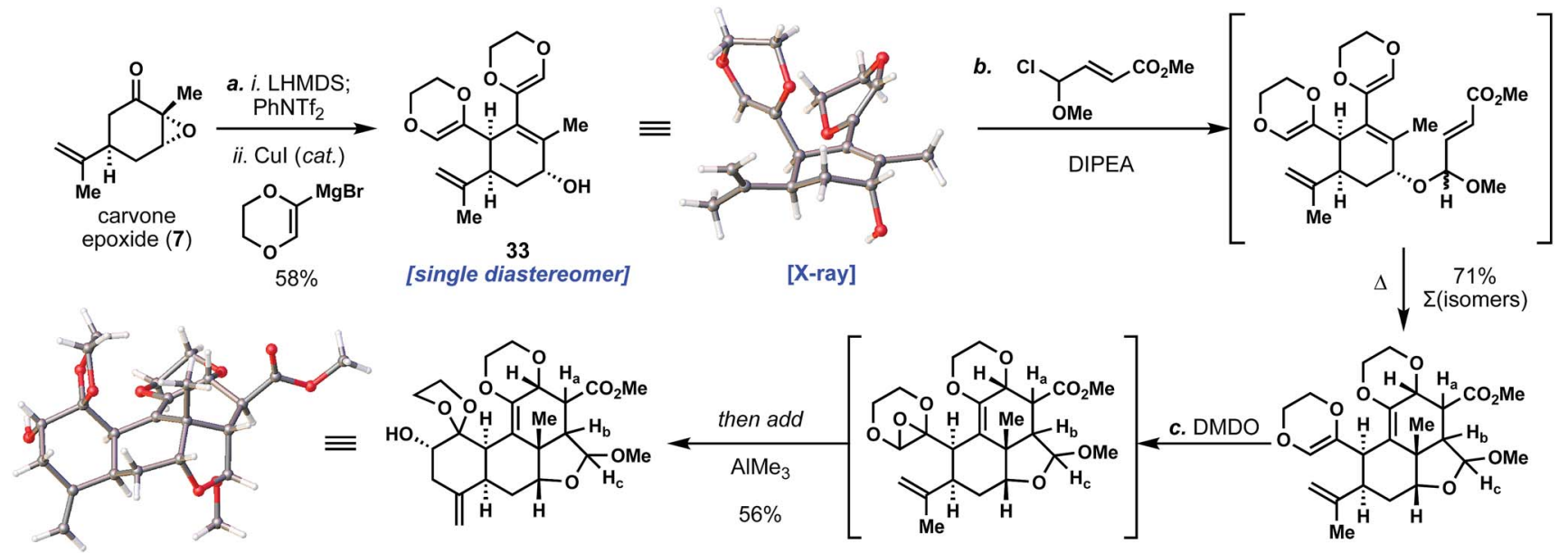

38, [X-ray]

37, $H_{a}=\beta ; H_{b}, H_{c}=\alpha$

38, $\mathrm{H}_{\mathrm{a}}=\alpha ; \mathrm{H}_{\mathrm{b}}, \mathrm{H}_{\mathrm{c}}=\beta$

34, $\mathrm{H}_{\mathrm{a}}=\beta ; \mathrm{H}_{b}, \mathrm{H}_{c}=\alpha, 35 \%$

35, $\mathrm{H}_{\mathrm{a}}=\alpha ; \mathrm{H}_{\mathrm{b}}, \mathrm{H}_{\mathrm{c}}=\beta, 27 \%$

36, $\mathrm{H}_{\mathrm{a}}, \mathrm{H}_{\mathrm{c}}=\beta ; \mathrm{H}_{\mathrm{b}}=\alpha, 9 \%$

Scheme 13 -Step synthesis of the quassinoid core architecture. Reagents and conditions: (a) LHMDS (1.0 equiv.), PhNTf 2 (1.0 equiv.), THF, -78 $\rightarrow 0{ }^{\circ} \mathrm{C}, 5 \mathrm{~min}$, then add a solution of Cul (0.35 equiv.) and dioxenyl Grignard (3.5 equiv.), THF, $0{ }^{\circ} \mathrm{C}, 16 \mathrm{~h}, 58 \%$; (b) DIPEA (4.0 equiv.), dienophile (2.0 equiv.), PhMe, $23^{\circ} \mathrm{C}, 12 \mathrm{~h}$, then add PhMe, HMDS, $110^{\circ} \mathrm{C}, 3 \mathrm{~d}, 71 \%$ ( $\mathrm{S}$ of isomers); (c) DMDO (1.0 equiv.) then add AlMe 3 (1.5 equiv.), DCM/ acetone $-40{ }^{\circ} \mathrm{C} \rightarrow 0{ }^{\circ} \mathrm{C}, 10 \mathrm{~min}, 56 \%$. LHMDS = lithium bis(trimethylsilyl)amide, $\mathrm{Tf}=$ trifluoromethanesulfonyl, DIPEA $=N, N$-diisopropylethylamine, $\mathrm{HMDS}=$ hexamethyldisilazane, $\mathrm{DMDO}=$ dimethyldioxirane.

(see bracketed intermediate, Scheme 1) was cleanly generated by treatment with DMDO and then subjected in the same pot to an assortment of Lewis acids. We found that trimethylaluminum proved to be an optimal mediator for both transformations, cleanly delivering secondary alcohols $\mathbf{3 7}$ and $\mathbf{3 8}$ in $56 \%$ combined yield. Both ene products were formed with comparable efficiency and as single isomers at the newly formed alcohol stereocenter. The stereochemistry of $\mathbf{3 8}$ was further confirmed by single crystal X-ray crystallographic analysis. Significantly, the quassinoid core architecture was thus completed in only three steps from 7. Five carbon-carbon bonds and seven stereocenters were formed in the process, speaking to the power of tandem catalysis combined with synthetic strategy to assemble ornate, highly complex structures with high efficiency.

\section{Conclusions}

In summary, we have developed a novel copper-catalyzed difunctionalization reaction that converts readily available epoxy ketones to highly substituted, diastereomerically pure allylic alcohols in one pot. This transformation features a diverse substrate scope, with many classes of nucleophiles and epoxides being tolerated. Additionally, this chemistry can generate modular products by careful control of reaction conditions. The utility of this process was then demonstrated in a rapid synthesis of the quassinoid core architecture, a structure common to many bioactive natural products and one whose syntheses have historically required numerous chemical steps. Future studies are focused on employing this methodology to rapidly access high value intermediates and other complex natural product-like structures as well as synthesizing diverse quassinoid natural products.

\section{Conflicts of interest}

There are no conflicts to declare.

\section{Acknowledgements}

T. J. M. acknowledges unrestricted financial support from Novartis, Bristol-Myers Squibb, Amgen, and Eli Lilly. T. J. M. is a Research Corporation Cottrell Scholar. M. L. C. acknowledges UC-Berkeley and the NSF for a Berkeley Graduate Fellowship and NSF Predoctoral Fellowship (DGE-1106400) respectively. S. J. H. thanks the UC-Berkeley College of Chemistry for a summer undergraduate research award. We are grateful to Dr Hasan Celik for NMR spectroscopic assistance. Dr Nicholas Settineri, Dr Simon Teat, and Mr Peter Waller are acknowledged for X-ray crystallographic analysis wherein support from NIH Shared Instrument Grant (S10-RR027172) is also acknowledged.

\section{Notes and references}

1 (a) A. M. Armaly, Y. C. DePorre, E. J. Groso, P. S. Riehl and C. S. Schindler, Chem. Rev., 2015, 115, 9232; (b) T. Newhouse, P. S. Baran and R. W. Hoffmann, Chem. Soc. Rev., 2009, 38, 3010.

2 Z. Guo, S. Vangapandu, R. W. Sindelar, L. A. Walker and R. D. Sindelar, Front. Med. Chem., 2009, 4, 285.

3 (a) F. L. Winckler, Repert. Pharm., 1835, 4, 85; (b) M. Cuendet and J. M. Pezzuto, J. Nat. Prod., 2004, 67, 269; (c) T. V. A. Tran, C. Malainer, S. Schwaiger, A. G. Atanasov, E. H. Heiss, V. M. Dirsch and H. Stuppner, J. Nat. Prod., 2014, 77, 483; (d) G. Fiaschetti, M. A. Grotzer, T. Shalaby, D. Castelletti and A. Arcaro, Curr. Med. Chem., 2011, 18, 316. 
4 For syntheses of quassin, see: (a) G. Vidari, S. Ferriño and P. A. Grieco, J. Am. Chem. Soc., 1984, 106, 3539; (b) N. Stojanac, A. Sood, Ž. Sojanac and Z. Valenta, Can. J. Chem., 1975, 53, 619; (c) N. Stojanac, Ž. Sojanac, P. S. White and Z. Valenta, Can. J. Chem., 1979, 57, 3346; (d) N. Stojanac and Z. Valenta, Can. J. Chem., 1991, 69, 853; (e) M. Kim, K. Kawada, R. S. Gross and D. S. Watt, J. Org. Chem., 1990, 55, 504; (f) T. K. M. Shing and Q. Jiang, J. Org. Chem., 2000, 65, 7059.

5 For syntheses of bruceantin, see: (a) M. Sasaki and T. Murae, Tetrahedron Lett., 1989, 30, 355; (b) J. M. Vander Roest and P. A. Grieco, J. Am. Chem. Soc., 1993, 115, 5841.

6 For syntheses of miscellaneous quassinoids, see: (a) P. A. Grieco, R. Lis, S. Ferriño and J. Y. Jaw, J. Org. Chem., 1982, 47, 601; (b) P. A. Grieco, R. Lis, S. Ferriño and J. Y. Jaw, J. Org. Chem., 1984, 49, 2342; (c) H. Hirota, A. Yokoyama, K. Miyaji, T. Nakamura and T. Takahashi, Tetrahedron Lett., 1987, 28, 435; (d) P. A. Grieco, D. T. Parker and R. P. Nargund, J. Am. Chem. Soc., 1988, 110, 5568; (e) K. Kawada, M. Kim and D. S. Watt, Tetrahedron Lett., 1989, 30, 5989; $(f)$ P. A. Grieco, R. P. Nargund and D. T. Parker, J. Am. Chem. Soc., 1989, 111, 6287; $(g)$ J. L. Collins, P. A. Grieco and R. S. Gross, J. Org. Chem., 1990, 55, 5816; $(h)$ R. S. Gross, P. A. Grieco and J. L. Collins, J. Am. Chem. Soc., 1990, 112, 9435; (i) R. S. Gross, P. A. Grieco and J. L. Collins, J. Org. Chem., 1991, 56, 7167; (j) T. J. Fleck and P. A. Grieco, Tetrahedron Lett., 1992, 33, 1813; (k) E. D. Moher, J. L. Collins and P. A. Grieco, J. Am. Chem. Soc., 1992, 114, 2764; (l) P. A. Grieco, J. L. Collins, E. D. Moher, T. J. Fleck and R. S. Gross, J. Am. Chem. Soc., 1993, 115, 6078; (m) P. A. Grieco and M. M. Piñeiro-Nuñez, J. Am. Chem. Soc., 1994, 116, 7606; (n) P. A. Grieco, S. D. Cowen and F. Mohammadi, Tetrahedron Lett., 1996, 37, 2699; (o) P. A. Grieco and J. D. Speake, J. Org. Chem., 1998, 63, 5929; (p) P. A. Grieco, J. L. Collins and J. C. Huffman, J. Org. Chem., 1998, 63, 9576; (q) T. K. M. Shing and Y.-Y. Yeung, Angew. Chem., Int. Ed., 2005, 44, 7981; (r) T. K. M. Shing and Y.-Y. Yeung, Chem.-Eur. J., 2006, 12, 8367.

7 Z. G. Brill, M. L. Condakes, C. P. Ting and T. J. Maimone, Chem. Rev., 2017, 117, 1753.

8 P. A. Wender, J. M. Erhardt and L. Letendre, J. Am. Chem. Soc., 1981, 103, 2114.

9 (a) J. E. McMurry and W. J. Scott, Tetrahedron Lett., 1980, 21, 4313; (b) W. J. Scott and J. E. McMurry, Acc. Chem. Res., 1988, 21, 47.

10 For a recent review on Cu-catalyzed cross couplings, see: S. Thapa, B. Shrestha, S. K. Gurung and R. Giri, Org. Biomol. Chem., 2015, 13, 4816.

11 For recent copper-catalyzed Kumada and Negishi-type crosscouplings of $\mathrm{sp}^{2}$ electrophilies, see: (a) S. Thapa, A. S. Vangala and R. Giri, Synthesis, 2016, 48, 504; (b)
S. Thapa, A. Kafle, S. K. Gurung, A. Montoya, P. Riedel and R. Giri, Angew. Chem., Int. Ed., 2015, 54, 8236; (c) L. Hintermann, L. Xiao and A. Labonne, Angew. Chem., Int. Ed., 2008, 47, 8246; (d) A. S. E. Karlström, M. Rönn, A. Thorarensen and J.-E. Bäckvell, J. Org. Chem., 1998, 63, 2517. For examples in synthesis, see: (e) J. Xuan, A. Zhu, B. Ma and H. Ding, Org. Lett., 2018, 20, 4153; $(f)$ C. Jonasson, M. Rönn and J.-E. Bäckvell, J. Org. Chem., 2000, 65, 2122.

12 In the absence of other factors, copper-catalyzed allylic substitutions often proceed with anti stereochemistry and $\mathrm{S}_{\mathrm{N}} 2^{\prime}$ regiochemistry; see: (a) E. J. Corey and N. W. Boaz, Tetrahedron Lett., 1984, 25, 3063; (b) N. Yoshikai, S. Zhang and E. Nakamura, J. Am. Chem. Soc., 2008, 130, 12862; (c) N. Yoshikai and E. Nakamura, Chem. Rev., 2012, 112, 2339; (d) W. Sheng, M. Wang, M. Lein, L. Jiang, W. Wie and J. Wang, Chem.-Eur. J., 2013, 19, 14126.

13 It is important to note that three reactions each occurring at around $80 \%$ yield would give an overall product yield of $c a$. $50 \%$. Indeed, yield for the triflation step alone is $82 \%$ in our hands. Wender's and McMurry's works likewise benchmark the allylic substitution and cross coupling processes respectively at $50-80 \%$ yields each. For a discussion on the challenges and opportunities of tandem process, see: D. E. Fogg and E. N. dos Santos, Coord. Chem. Rev., 2004, 248, 2365.

14 In light of the high reactivity of allyl-type nucleophiles, this process may involve a non copper-mediated background reaction. Similar challenges are noted in copper-catalyzed conjugate addition reactions employing allylmagnesium halides.

15 For the use of vinyl dioxenes as dienes in cycloadditions, see: (a) M. Fétizon, P. Goulaouic, I. Hanna and T. Prangé, J. Org. Chem., 1998, 53, 5672; (b) V. Blanchot-Courtois, M. Fétizon and I. Hanna, Tetrahedron Lett., 1992, 33, 5061.

16 For a recent, impressive use of dioxene in total synthesis, see: A. G. Kravina and E. M. Carreira, Angew. Chem., Int. Ed., 2018, 57, 13159.

17 Valenta has demonstrated the remarkable exhaustive deuteration of neoquassin under basic conditions:

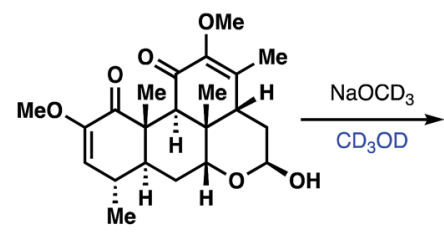

neoquassin

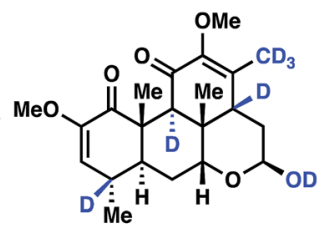

neoquassin- $d_{7}$ see: Z. Valenta, S. Papadopoulos and C. Podešva, Tetrahedron, 1961, 15, 100 and ref. 4b.

18 C. Baylon and I. Hanna, Tetrahedron Lett., 1995, 36, 6475. 